\title{
The Role of Family Coercion, Culture, Expert Witnesses and Best Practice in Securing Forced Marriage Convictions
}

\begin{abstract}
Forced marriage (FM) affects many communities in the UK and has far-reaching consequences for individuals and society. In light of the UK's new FM legislation, introduced in 2007 and 2014, this paper analyses the UK's first successful FM prosecution, concerning a mother who forced her daughter into marriage overseas. This case study highlights the importance of understanding the role that culture (including family values and norms) plays in FM, both in terms of achieving successful prosecutions and providing effective assistance to victims. This understanding is best developed by including intermediaries in police investigations and expert witnesses in the courtroom. The paper also explores how expert witnesses and intermediaries help realise the new legislation's potential to empower victims.
\end{abstract}

Key words: expert witnesses, forced marriage, coercion, consent, policing, best practice.

\section{Key messages}

o FM often takes place in cultural and familial contexts with patriarchal power systems. A better understanding of these factors is key in developing best-practice to assist victims more effectively.

o Successful prosecution of cases FM relies on victims feeling empowered to come forwards; providing specialist intermediaries to support them during police investigations is a critical element. Intermediaries can explain to police and support services the specific socio-cultural dynamics involved and how these can affect a victim's mindset and behaviour, especially with regard to coercive family tactics. 
o Expert witnesses play a vital role in assisting legal and law-enforcement practitioners to understand the religious and socio-cultural context (e.g. different marriage practices and traditions) underpinning individual FM cases to ensure that effective prosecutions can be brought.

\section{Introduction}

A forced marriage (FM) is an illegal and invalid marriage that takes place without the consent of one or both parties, often as a result of coercion. The Oxford Dictionary defines coercion as "persuading” an individual to do something through two important means: (a) acts of force or active pressure, and/or (b) physical and/or non-physical forms of explicit and/or implicit force and threats, particularly psychological pressure.

Controlling and coercive behaviours are the product of complex relationship dynamics, personality traits, personal histories and individual choices; however, socio-cultural factors can affect and contribute to the ways in which controlling and coercive behaviours present (removed for review; Longman and Bradley 2015). Coercive and controlling tactics are often used in concert to create an environment in which the victim feels there is no meaningful alternative but to submit to the demands of others (Callaghan, Alexander., Sixsmith and Fellin, 2018). Coercive behaviour is now legally recognised in the UK as a criminal offence and a form of domestic abuse in an intimate or family relationship (s.76 of the Serious Crime Act 2015). This provides statutory recognition that a perpetrator can cause serious emotional and psychological harm even when the abuse stops short of physical or sexual violence. The statutory guidance on this legislation acknowledges that such behaviour is primarily targeted at women and girls, and is "underpinned by wider societal gender inequality" (Home Office 2015: 7). 
Controlling and coercive behaviour is often used to force women and girls into marriage, which can-and often does—-lead to a range of other serious harms, including abduction, domestic violence, rape, forced pregnancy and domestic servitude (Anitha 2019; Chantler and McCarry 2019; Gangoli et al. 2006; Hester et al. 2008; removed for review; Outtara et al. 1998). FM is a serious violation of an individual's human rights, including the right not to marry and the right to freely consent to marry. Both children and adults may be forced into marriage: forcing a child to marry is a form of child abuse. Refusing or trying to escape an FM often puts victims at risk of honour killings and/or other forms of 'honour'-based violence (removed for review).

The UK Government's Forced Marriage Unit (FMU) supports 1200-1400 victims each year. Naturally, that figure does not include those who do not or cannot seek support, so the true number of victims is believed to significantly higher (removed for review). In the UK, FM largely affects women and girls from black and minority ethnic (BME) communities. Most are women of South Asian origin, with the next largest group being women of Middle Eastern origin (FMU 2018), though the latest data indicate recent changes in the ethnic profile of those affected: since 2016, there has been a 100\% year-on-year increase in the number of cases involving Somali children and teenagers (FMU 2018).

\section{Forced marriage legislation in England and Wales}

Efforts to counter FM are becoming increasingly visible in British criminal justice. From June 2014, FM became a specific offence in England and Wales under s.121 of the Anti-Social Behaviour, Crime and Policing Act: it carries a maximum seven-year prison sentence (removed for review). Before this, prosecutors used more general legislation covering false imprisonment, kidnapping and violence for FM cases. In civil legislation, the Forced Marriage (Civil Protection) Act 2007 enables courts to issue Forced Marriage Protection Orders (FMPO), a form of injunction that prohibits persons from committing acts that might lead to a named 
individual being forced into marriage. Breaching the terms of an FMPO is a criminal offence carrying a maximum five-year sentence. Pursuant to s.63A (1) of the Family Law Act 1996, a potential victim, a "relevant third party”, or any other person with the court's leave (or the court itself) may seek an FMPO to protect a potential victim or someone who has been already forced into marriage. Since the introduction of this legislation on 25 November 2008 until 31 December 2018, 1943 FMPOs were applied for, 1598 for women: 1856 were granted.

FMPO applications are primarily concerned with risk management, requiring the court to evaluate the necessity for state intrusion into family life versus the need to protect an at-risk person from harm. The court must therefore consider an individual's circumstances and collate evidence to determine the level of risk. The evidence may come from a number of sources; a victim could disclose directly to the police or other statutory agency, resulting in a paper-trail (often digital nowadays), or could provide records of invitations from extended family to travel overseas, the purchase of wedding-related items and so forth. Similarly, a GP, teacher, therapist or charity worker might provide witness evidence. Police may also have encounters with family members that trigger concern. The arrest of a potential perpetrator, particularly for offences such as assault or kidnap, may result in the victim disclosing the risk of FM: this should lead to a proactive risk assessment under current policy. In other cases, FMPOs may be used to facilitate the repatriation of victims who are overseas but have disclosed to parties in the UK that they are at risk or have already been forced into marriage.

The key issue is that victims and potential victims may come to the attention of authorities in a range of ways involving a variety of sources of evidence, some confidential. It is vital that, despite these differences, professionals are able to recognise indicators of, and risk factors for, FM so that they can effectively evaluate potentially disparate, incomplete and even inconsistent evidence. Despite these challenges, two successful FM convictions (Regina $v \quad R B$ 
[Birmingham] and Regina $v M$ and $B^{2}$ [Leeds]) were recently secured in the UK after the victims disclosed their situation to the authorities.

Regina v RB came before Birmingham Crown Court on 30 April 2018 and involved the mother of a teenage girl being prosecuted under two subsections of the Anti-Social Behaviour, Crime and Policing Act, that is FM- specific: practising deception to cause the victim to leave England and Wales, pursuant to s.121(2), and using coercion to force her daughter into marriage upon arrival in Pakistan (the Act has extra-territorial jurisdiction), pursuant to s.121(1). Throughout the trial the defendant denied the charges, asserting that her daughter had "agreed" to the marriage and was “ready”. However, on 22 May 2018, she was found guilty on two counts of FM, for which she was sentenced to three-and-a-half years, and also one count of perjury, for which she was sentenced to one additional year (Summers 2018). This case illustrates not only the key elements in a successful investigation of FM, but also how a conviction was secured using new FM-specific legislation; it offers a powerful demonstration of the importance of understanding the role that cultural and family dynamics, traditions and values play in FM cases, and how the new legislation can empower victims.

\section{Regina $v R B$}

The authors both worked on this case (the first author was the expert witness and the second, the prosecutor), so the insights presented below are based on their knowledge and experience of how the case progressed from disclosure through to investigation, conviction and sentencing. For legal reasons, the defendant cannot be named.

The defendant was born in Pakistan and immigrated to the UK in the 1990s to join her thenhusband, who was from the village she grew up in. Before divorcing acrimoniously, the defendant and her husband had four children, including the victim. The children resided with their mother until she returned to Pakistan for five months in 2005, leaving the children in the 
permanent care of their father. While overseas, the defendant married a Pakistani national. When she returned to the UK, only two of the children resumed living with her, including her youngest daughter - the victim. Her new husband remained in Pakistan until he was granted a spousal visa and joined his wife in the UK in 2009.

In 2012, the defendant took the victim, then aged thirteen, to Pakistan to stay with her second husband's family. During this time, a ceremony was conducted to marry the victim to her stepfather's twenty-nine-year-old nephew. Given the victim's age, this 'marriage' was not lawful under either Pakistani or British law. Nonetheless, the groom took advantage of his marital 'rights' to have sex with the victim: she became pregnant.

When the victim returned to the UK, she told a school counsellor that her mother was taking her to the doctor because she had missed her period. Although the victim did not recognise the significance of this, the counsellor and the GP did: both independently alerted children's services. The police were not informed at this stage, but a social worker interviewed the mother and daughter informally to determine whether there were any child protection issues. The child was not removed from her mother's care prior to this interview, nor was her father informed of the situation. Neither the victim nor the defendant told the social worker about the marriage ceremony. Instead, the defendant told the social worker that the father of the unborn child was himself a teenager. She claimed that, though she had considered him a prospective husband for her daughter, because they had had sex while her daughter was underage all ties with him and his family had been severed when the family returned from Pakistan.

Social services accepted this explanation without challenge. They undertook no wider investigation of the defendant's family structure, the age of the man who had impregnated the victim, or the relationship between the defendant, the victim and the father of the unborn child. They also did not explore the veracity of the mother's assertion that a relative in Pakistan was 
terminally ill, which is why they had been there when the victim became pregnant. Since the supposed sick relative was the defendant's new mother-in-law, and therefore unrelated to the victim, social services should have questioned why the victim was required to accompany her mother when this involved being taken out of school during term time-something the school was not made aware of in advance. Moreover, rather than applying for a holiday visa for her British daughter, the defendant applied for a Pakistani identification card, giving an address in Pakistan as her daughter's place of residence. Thus, although social services should have investigated further, significant warning signs were either misunderstood or ignored.

The victim underwent an abortion in 2012. Her behaviour changed markedly over the following year: she began drinking, taking drugs and engaging in sexual behaviours that placed her at serious risk of exploitation. In 2013, the victim was deemed "beyond parental control" and her mother agreed to her being accommodated by the local authority under s.20 of the Children Act 1989 Although children's services did not appear to appreciate the significance of the 2012 Pakistan trip, or the implications of what occurred afterwards, the victim's subsequent entry into the care system did offer her some level of protection: the defendant was forced to wait for a new opportunity to remove the victim from the UK so that the 'marriage' could be legalised in both jurisdictions when the victim turned eighteen.

In December 2015, the victim was moved from a children's home to semi-independent accommodation close to her mother's residence; she began visiting her mother daily. In early 2016, the defendant returned to Pakistan. The victim struggled to cope with her absence and the lack of boundaries afforded by her new living arrangements, repeatedly absconding from her accommodation. Upon her mother's return, the victim chose to spend most nights at her mother's home and made it apparent that she wanted to live with her again. The defendant told children's services that she wanted her daughter back home and threatened legal action if they refused. 
During the trial in May 2018, the Crown Prosecution Service (CPS) argued that the defendant used her daughter's attachment and fear of abandonment to encourage her to resist accepting independent accommodation. The defendant's subsequent offer to take the victim on a family holiday to Pakistan in August 2016 was a significant inducement to ignore what had happened last time, given that the victim was a young person who had been separated from her family for four years. The defendant also told the victim that she would receive an iPhone 6 on her birthday if she went on the trip. Since the victim's eighteenth birthday was approaching, children's services did not think it appropriate to apply for an interim care order when informed of the trip. Thus, when the defendant requested the return of her daughter's passport, it was provided.

The defendant and victim left for Pakistan two weeks before the victim's eighteenth birthday (August 2016) using airline tickets police later discovered were transferable, allowing the defendant to change the return date without her daughter's knowledge. The day the victim turned eighteen, she attended what she thought was a birthday party. Instead, she found herself being congratulated on her forthcoming marriage; the man involved in the ceremony that had taken place when she was thirteen appeared, bearing the promised iPhone. Over the next ten days, the defendant used psychological and emotional pressure to coerce her daughter into marrying him. When her daughter resisted, the defendant threatened to destroy her passport and disown her. The victim eventually, but unwillingly, participated in a Mehndi (pre-wedding celebration), a marriage ceremony and a Walima (post-wedding party); she was then sent to live with her new husband and in-laws.

Children's services had previously given the victim a pre-paid phone in case of emergencies, but this disappeared before she left the UK. The defendant had also encouraged her daughter 
to leave her normal phone at home, despite the fact that the victim would have no easy access to the internet or other phones in Pakistan. Secretly using her mother's mobile phone, the victim managed to send WhatsApp calls and messages to her sister asking for help. The victim’s sister alerted their father, who in turn alerted children's services and the police.

Two months after the 2016 marriage, the defendant returned to the UK without her daughter. She was immediately summonsed to attend the High Court, as children's services had initiated proceedings for an FMPO. Under oath, the defendant denied that her daughter had been forced into marriage. However, this statement was proven false when the victim's sister provided the court with the WhatsApp messages. An FMPO was then made ordering the defendant and her second husband to secure the victim's immediate return to the UK. The defendant complied, contacting the family in Pakistan and directing the groom to take the victim to the airport the following day; a plane ticket purchased by children's services was waiting. The fact that the groom and his family made no efforts to assert the validity of the marriage demonstrates the extent of the defendant's control over her daughter, though the immediate compliance of the Pakistani groom and his family show that they had colluded in the FM.

\section{Prosecuting FM cases}

The role of expert witnesses

Expert witnesses feature prominently across many areas of criminal and civil law; a large body of scholarship shows that expert witnesses are effective at swaying jury decisions in both contexts. For example, in a series of simulated murder trials, jurors who heard expert testimony for the defence were consistently more lenient toward defendants (Schuller and Rzepa 2002). However, the literature suggests that expert testimony does not affect jurors equally (Cole and Dioso-Villa 2009; Huey 2010; Schweitzer and Saks 2006): jurors' responses to expert testimony are mediated by their beliefs about forensic science, as measured by individuals' 
exposure to crime-drama television shows (Shelton et al. 2007). The successful prosecution of Regina $v R B$ depended on strategic use of evidence, the development of trusting relationships between the police and the victim, and expert witness testimony. The CPS was conscious of the importance of explaining the cultural and religious pressures, nuances and unwritten rules at play in terms of how and why the victim was forced into marriage; the prosecution team also took pains to explicate the socio-cultural complexities of the dynamic between the defendant and victim. The first author provided an expert report for the prosecution, explaining the victim's socio-cultural background and how it may have affected her belief system, as well as how a marriage would have been organised culturally, socially and legally within the family and community into which her mother had married for the second time.

The prosecution's case was that the defendant sought to impose control over her daughter to curb behaviours that challenged her as a parent and caused familial shame (e.g. her daughter's awakening sexuality). Her response was to arrange what she perceived to be a suitable, even attractive, marriage using her extended family network, thereby meeting familial expectations and strengthening existing kinship ties. It is noteworthy that the victim’s parents' marriage had been arranged by their families. However, in sharp contrast to the defendant, the victim's father described in court how "in those days" he had felt unable to challenge his parents' choice of wife; he also stated that the two children who had lived with him since 2005 had both made “love” choices when selecting their marital partners. Thus, while the defendant's 'solution' to what she perceived as the difficulties arising from her daughter's burgeoning sexuality were no doubt shaped by her cultural background, the approach of her former husband (who also came from the same cultural heritage) makes clear that her choice to force her daughter into marriage was not the inevitable product of her background. It is vital to avoid essentialising cultures - an issue that expert witnesses are able to speak to eloquently - and, instead, look at the range of choices, behaviours and values present in all cultural groups (removed for review). 
The first author, as expert witness (removed for review), explained to the court why the 2016 marriage ceremony might not be recognised as such by those unfamiliar with the community concerned; the 'marriage' consisted of an imam visiting the victim at a beauty salon while she was being dressed for her wedding. In the presence of her mother, but not the groom or any independent witnesses (though there were other women present preparing for their own weddings), the victim was asked if she wished to marry. Against the backdrop of her mother's threats—including the familiar coercive tactic “After all I've done for you...”- she was pressured into saying yes. As she and the groom saw the imam and signed the wedding certificate separately, the victim next met the groom only after the 'marriage' had been contracted and announced at the Walima, where the couple were presented to two hundred and fifty guests as husband and wife.

Upon arriving back in the UK in October 2016 after the FMPO was issued, the victim was met by police and a social worker. In an attempt to protect her mother, the victim initially denied that any marriage had occurred; however, once reunited with her sister, she produced photographs of the wedding and explained how she had been forced into it. The victim attended a High Court hearing (1 November 2016) where the fact of the marriage was established and the defendant admitted to having lied under oath at the initial hearing. The judge then directed that the CPS be informed of the defendant's lies in his court so that the CPS could also consider investigating this act of perjury. Following the issuance of the FMPO, the police had already initiated an independent investigation regarding the FM.

As that investigation proceeded, the significance of what had occurred in 2012 became apparent. The police then sought expert advice from an experienced officer in the Metropolitan Police Service, and also academic experts and charity workers, as well as obtaining records from GPs, the victim’s school, children's services and counselling services. The victim was assessed as having 'early experience trauma' arising from lengthy absences from formal 
schooling as well as significant attachment issues, resulting in difficult and often risky behaviours. There had clearly been inadequate investigation of the victim's situation when she became pregnant at age thirteen. This shows the importance of collecting all relevant records through cross-agency cooperation; once collated, the body of information available to police enhanced their understanding of the socio-cultural context of the case (Hallet, 2017; Skidmore, Garner, Crocker, Webb, Graham and Gill, 2016).

Having experts to assist legal and law-enforcement practitioners with understanding the sociocultural context and marriage traditions for different countries, cultures and religions proved invaluable in this case, as it has in similar cases, such as that of Shafilea Ahmed ${ }^{1}$ (removed for review). In the investigation and trial of Regina $v R B$, experts were able to shed light on broad issues of cultural life in Pakistan and the Pakistani diaspora, offering insights into factors such as gender inequalities, honour systems, patriarchal values and traditions, immigration concerns, and how and why control over female sexuality manifests in general and specific forms of gender-based violence. Understanding these factors was critical to grasping the effectiveness of the coercive means used by the defendant.

Without expressing it directly, in court the victim revealed a genuine sense of powerlessness in the environment in which her mother had placed her, both in 2012 and 2016. Thus, the jury was able to understand why, even though the victim had signed the marriage certificate, attended the wedding party dressed immaculately, and participated in a photoshoot with her husband, she had actually not chosen to do any of these things of her own free will. Rather, she had been unable to challenge what was happening because her mother had undermined her attempts to assert her own agency through the consistent application of various forms of coercion in both the UK and Pakistan (removed for review; Madhok, Phillips and Wilson 2013; Munro 2010). 
For a coercive threat to be valid in the legal context, the coercer must be in a position to carry out the negative consequences threatened, or the coerced party must reasonably believe that the coercer is in a position to do so. However, this does not mean that the coercer must be able to directly carry out the threat: critically, in this case, the victim believed that her mother was in a position of sufficient authority, with effective control over the threatened consequences and the situation in general (removed for review). For instance, the victim was afraid of the possible consequences of challenging her mother in Pakistan, including potential abandonment and the certainty that the wider community would see rejection of the marriage as a source of considerable shame for the entire family. It is not the existence of choice, but the ability to freely engage in the process of choice, that is key to determining consent versus coercion (removed for review, 2017). In this case, the mother actively interfered in this process by using threats and other coercive and deceptive measures such that her daughter was not in a position to consent.

Indeed, at sentencing the judge intimated that the defendant viewed the victim's FM as a commercial transaction in which the victim was commodified. He suggested that the trade-off for the groom and his family for marriage to a girl who would in their cultural terms have been considered wholly unsuitable (the victim had had a series of sexual encounters following her return from Pakistan in 2012, used drugs, smoked and drank alcohol, and was not a practising Muslim) was a spousal immigration visa to the UK. As yet, there are no sentencing guidelines for this form of offence; the Sentencing Guidelines Council will need to tackle the transnational nature of such crimes in future. Factors marking culpability in such cases will have to include the deliberate use of marriage to secure immigration status for a spouse and perhaps extended family members, other motivating factors behind the use of FM, whether sexual activity and childbirth followed the FM, and the nature of the coercion applied. 


\section{Achieving best evidence: lessons for the police in victim-care and the use of intermediaries}

A fundamental challenge in preventing (or at least improving outcomes in) FM cases is victims' inability to access appropriate services. Although the police in Regina $v R B$ directed the victim to charity-sector partners, their skilled intervention was hampered by the fact that the situation had been ongoing for so many years; this meant that the victim required intensive, long-term assistance to address the trauma and other difficulties her experiences between 2012 and 2016 had caused. A further complication was that the victim displayed challenging behaviours; she was particularly suspicious of the police, lawyers and various legal processes involved in the case.

The victim chose to provide her pre-trial evidence in the form of police statements rather than a pre-recorded interview, and her initial statement was taken without the benefit of an intermediary. After the defendant was charged, the CPS requested a conference with the police during which they recommended that an intermediary be engaged to assess the victim, report on her vulnerabilities, and advise the police on how they could most effectively obtain further evidence through additional statements. Counsel also directed the police to collect and collate third-party materials, including documentation from social services, the victim's school, GPs and children's services to create a full picture of the victim and her situation. Given that the victim's reliability and credibility would inevitably be called into question by the defence, this strategy of proactive disclosure management and active case-building meant that the police and CPS could establish a comprehensive understanding of the victim's experiences from 2012 onwards.

Over the years, the victim had experienced a high level of intervention from statutory services. Gathering, collating and assessing all this material proved key to the successful prosecution of the case, but this work only commenced after the October 2016 investigation had begun. The 
materials gathered provided rich evidence of a controlling mother struggling to deal with her daughter's burgeoning sexuality and the impact of her 'solution' on an already vulnerable child; the victim's response of engaging in risky behaviours cemented the defendant's belief that the best way to control her daughter's sexuality was to formalise the 2012 'marriage' as soon as her daughter turned eighteen.

The police worked hard to build trust with the victim, separating investigative and safeguarding roles by appointing an intermediary to undertake all safeguarding duties. Separating these roles enabled investigators to focus on their enquiries, while a police liaison officer took ownership of the victim's care. The police liaison officer provided consistent and reliable ongoing support for the victim and, through continued contact and clear boundaries, helped develop her confidence in the legal process, which was critical to the victim remaining involved throughout the trial. Considerable care was taken to handle interactions appropriately; a contact protocol was devised by the police to ensure transparency and full compliance with disclosure obligations.

The intermediary assisted this process in numerous ways, including helping the prosecution to recognise specific trauma triggers that resulted in reactive and often self-sabotaging behaviours in the victim. This process also allowed the intermediary to outline the victim's linguistic and cognitive abilities, helping counsel formulate effective questions to elicit reliable, accurate testimony, while reducing the risk of secondary trauma (Henderson 2015; Plotnikoff and Woolfson 2015). Engaging the intermediary made plain the need for examination and crossexamination to be carefully managed; as a result, a 'ground rules' hearing was held to determine the parameters and form of questioning best suited to securing the victim's best evidence in court (Henderson 2015). Under Criminal Procedure Rules (2015), when preparing for trial courts must take every reasonable step to facilitate the participation of witnesses and defendants. Meanwhile s.29 of the Youth Justice and Criminal Evidence Act 1999 provides for 
any and all examinations of a vulnerable witness to be conducted through an intermediary, who communicates questions to that witness and, if required, communicates their answers back to the questioner, explaining them where necessary (Henderson 2015). During the 'ground rules' hearing the questions that the CPS and defence were planning to ask the victim were subject to stringent judicial scrutiny. The CPS also decided to change the traditional order in which witnesses appeared, presenting the victim's evidence after that of other witnesses so that the jury was fully apprised of the victim's history, background and reasons for certain behaviours before hearing from her. The defence's co-operation with this tactic further demonstrated how a collaborative working relationship between professionals in such cases can assist in minimising secondary victimisation without undermining the fairness of the trial process (Plotnikoff and Woolfson 2015).

Thanks to these measures, despite the victim's considerable trauma and the significant distress caused by testifying against her mother, she was able to clearly describe for the jury her situation in the UK and Pakistan, the methods of coercion used and how they made her feel. Although the victim lacked sophisticated language and conceptual skills, she was still able to explain the process of deception and manipulation her mother had employed to secure her agreement to leave the UK in 2016. She detailed her reliance upon her mother as she approached the end of her time in care and how her mother encouraged her to return home and give her passport into her care. The victim also informed the jury of how her mother had created conflict between her and her social workers, noting her mother's anger and hostility towards children's services and her undermining of various protective measure put in place by them. She then explained how the trust she placed in her mother - trust that the 'holiday' to Pakistan signified her mother's love and acceptance—-was betrayed.

The victim told the court that when she arrived in Pakistan her mother convinced her it was unsafe for her to leave the house alone because she was a Western female. She also explained 
the psychological impact of being part of a new family group with different social rules and behaviours, particularly regarding gender roles and expectations. She had no money, her mother held her passport and she did not know where she was geographically, only that she was a considerable distance from the airport. Without access to her normal support structures, the victim did not understand which institutions she could seek help from. Moreover, she had no independent internet or phone access, relying instead upon sporadic and surreptitious use of her mother's phone. Her inherent lack of self-confidence and low self-esteem were major factors in how her mother was able to coerce her into marriage in this situation. However, her mother also refused to listen to her protests, threatening to disown her and asserting her disappointment in her daughter for not wanting to do this “one small thing”.

The victim's account of the 'marriage' celebrations and process made a strong impact on the jury's verdict, including on the count of perjury; naturally, this also had a significant impact on the jury's appraisal of the veracity of the defendant's testimony as a whole. Conducted over a number of days at a variety of venues, and involving elaborate traditional clothing, the 'marriage' celebrations culminated in a Walima attended by two hundred and fifty guests; the jury found the defendant's account that these arrangements had all been made in just two weeks after they arrived in Pakistan, and her reasons for all the family in the UK being excluded, were not credible. The defence supplied the police with video footage of the celebrations, but this footage was later proven to have been significantly edited; it then became part of the prosecution's case as it provided evidence of the defendant's controlling and manipulative behaviour. Similarly, the marriage certificate that the victim signed, which the defendant later gave to police as evidence of her daughter's willing consent, supported the prosecution's contention about the level of deception the defendant had employed. The certificate asserted that the victim's address was in Pakistan and that her stepfather (who was in the UK when the wedding occurred) was acting as her guardian (a role that must be undertaken by the bride's 
natural father under Islamic law). Indeed, all the roles formally required as part of the Pakistani wedding process were undertaken by members of the defendant's second husband's family.

These disclosures and explanations show that as the victim's trust in the police and criminal justice system grew-largely through a shrewd choice of victim liaison officer and the diligence of the investigating officers on the case-she was able to present a more comprehensive narrative. Indeed, the clarity of the victim's evidence developed in parallel to the police and prosecution's knowledge and understanding of the case. Thus, in FM cases such as Regina $v R B$, the importance of building trusting relationships, separating investigative and safeguarding functions, and making the right choice of police liaison officer (i.e. one who offers continuity, consistency and reliability) cannot be overstated.

\section{Key learnings}

\section{Protecting and supporting victims}

FM victims often face a stark choice between complying with familial wishes or being completely ostracised by their family and community (removed for review). Some are at risk of physical violence or, as the Shafilea Ahmed case demonstrates, murder (removed for review). Even with significant external support, the effects of losing long-term relationships and support structures are devastating (Love, Dank, Esthappan and Zweig, 2019) The police cannot provide an alternative for a lifetime of relationships; thus, once the criminal justice process concludes, significant ongoing support and assistance are required to help victims build new lives (removed for review, 2018).

This case demonstrates that one of the key challenges for prosecutions is overcoming the barriers preventing victims from reporting both FM and concerns about the risk of FM (removed for peer review, 2017). Proper awareness of, and effective responses to, reports must 
become the norm. The victim in this case did not report what was happening to the authorities herself; instead it was her sister who brought the FM to the attention of the relevant statutory agencies. However, although children's services had actively considered applying for an FMPO in 2016, they did not do so and the police were not made aware of their concerns. Even when the police were finally informed, this information came through a third party. Indeed, the successful prosecution was possible largely due to the fact that the police were able to access considerable evidence of the defendant's alarming behaviours because the victim had been in the care system. Women and girls without access to support services, those whose family members and/or community are complicit, and those whose lives do not intersect with statutory agencies are unlikely to be identified by third parties: in these cases, victim disclosure offers the only realistic prospect of assistance. As FM can also be committed by British citizens and residents who travel to another jurisdiction to marry, serious questions arise as to how those whom they 'marry' may be identified and informed of their fundamental rights to choose their marriage partner. Thus, moving forwards, best practice guidelines need to be developed to improve statutory agencies' recognition of risk factors and warning signs to increase the rate of prevention, or at least early intervention.

Understanding the role of socio-cultural factors and transnational elements

The fact that FM is a mechanism through which one person is controlled by one or more others is central to understanding this crime. While the desire for control plays out in many different ways, FM most often arises in families and communities in which patriarchal power systems are the norm (removed for peer review). The defendant in Regina $v$ RB is part of the Mirpuri diaspora in Britain and maintained close links with Pakistan; her second husband is a Pakistani national from the Punjab, a place she visited regularly and in which she had a home. The defendant's background and the relevant socio-cultural norms, values and traditions are crucial to understanding her decision to force her daughter to marry a Pakistani national overseas. 
Indeed, the defendant was only able to commit the offences through her knowledge of the local community in Pakistan, her extended family network there and the failure of UK statutory agencies to robustly address the risks they had identified in early 2016. Illuminating and explaining this for the jury relied on partnership between the expert witness (i.e. the first author, see (removed for peer review) and the prosecution team.

This case is a clear example of how a transnational FM "exploits boundaries and jurisdictions as strategic advantages” (Jamieson 2001: 377). It gave the defendant a means of exerting control over her daughter in Pakistan that she did not have in the UK, particularly given the protection afforded by the UK care system (despite the criticisms that may be made of their actions, particularly in 2012). Although the victim speaks fluent Urdu, and is Muslim and of Pakistani heritage, she is also a British teenager who was raised in the UK and had only visited Pakistan occasionally. By taking her daughter to a different environment, in which different legal and social rules and values apply_as well as removing her support network and denying her access to money, means of communication and an exit from the situation-the defendant was able to exploit her daughter’s vulnerabilities and coerce her into marriage.

To bolster the likelihood of further successful FM prosecutions, victims must be empowered to come forwards. Support services must also become more attuned to FM dynamics in order to adequate assess and address risk factors. There is a general reluctance in children's services to use care proceedings for older children (Dickens, Masson, Garside, Young, Bader, 2019); since most victims in FM cases are over sixteen, this approach needs to change for those at potential risk of this and related crimes (removed for review). There is also an assumption that many young people leave their family home when they try to escape abuse. However, it is rare for South Asian teens and young adults to move out of the family home before marriage; doing so often has long-term implications for family and community acceptance and even the young person's ability to marry within the community (Mayeda, Cho and Vijaykumar, 2019). 
Understanding FM and the contexts in which it is most likely to occur will better equip services to offer victims the support they require. It will also enable them to recognise the specific forms of risk and coercion involved, and the particular ways victims may respond because of their socio-cultural values and experiences (removed for peer review).

\section{Conclusion}

Until recently, forms of violence experienced primarily by BME women, such as FM, were neglected in both academic literature and policy debates: now they are often hyper-visible without necessarily being well understood (removed for peer review). Traditionally, domestic violence has been understood as primarily perpetrated by male partners and ex-partners; today, increasing attention is being directed to forms of violence against women and girls (VAWG) committed by relatives (including female relatives) from the wider kin-group, rather than just the immediate family. Although cultural specificities must be recognised when shaping legislation and prosecuting offenders, as demonstrated in Regina $v R B$, such recognition does not mean that minority cultures should be blamed (removed for peer review).

There is a difference between wholesale condemnation of the culture of a socio-ethnic group and condemnation of the harmful, illegal practices of some members of that group. Understanding the violence experienced by BME women in Britain requires an approach that takes account of the continuities between different forms of VAWG, irrespective of the cultural context in which it is perpetrated, while also addressing the specificity of particular forms, such as FM (removed for review); only then will efforts to address VAWG in general, and FM in particular, move beyond simplistic cultural essentialising of particular ethnic groups.

The causal factors behind Regina $v R B$ are far more complex than the British media's tale of backward parents and progressive British society. Looking ahead, it will be important to address the harmful effects of patriarchal cultural practices, no matter which culture they are 
associated with. Preventing these harmful practices will only be possible if the current monofocus on culture is replaced by a more complex, nuanced, intersectional understanding that looks at the various types of inequality that lie behind not just FM, but all forms of VAWG.

In this case, the prosecution argued that the defendant's compliance with the legal proceedings was based on her expectation that her daughter would not disclose the FM because of her love for, and desire to protect, her mother. This belief was initially borne out by the victim's stance upon her return from Pakistan in 2012 and initially in 2016, demonstrating that one of the key barriers to reporting and prosecution is the strength of familial loyalty and affection. Despite the defendant's belief that her daughter would not testify against her, she eventually did so with the help of an intermediary; this led to the defendant being convicted of two offences of FM and an offence of perjury, for which she received a total sentence of four and a half years' imprisonment.

When an investigation and subsequent trial are handled well, as they were in this case (at least as regards the response of statutory agencies after the second 'marriage' in 2016), the legal system can both protect and empower women. This sends a strong message that women who are subjected to deception and coercion in the process of securing an unwanted marriage will be supported if they feel able, or are enabled, to challenge these practices. A key lesson is the need to improve victims' awareness of, access to and confidence in the protections of criminal and civil law. In this case, the sensitive way in which police officers handled the victim, the early investigative advice provided by an experienced CPS lawyer, the early involvement of counsel, and the clear division of safeguarding and investigative functions were critical in securing a successful prosecution.

The case also demonstrates the value of multi-agency collaboration, including looking to other sectors (including the charity sector and academia) for the expertise needed to shed light on the 
cultural, social, religious and legal contexts of the actors involved. Following her mother's conviction, the victim spoke of her pride at having participated in the criminal proceedings, demonstrating the value of enabling the victim to be part of challenging the serious offences her mother had committed against her. However, better understanding of risk factors and warning signs could have enabled statutory agencies to intervene in 2012, protecting the victim from years of additional trauma. While successful prosecutions are vital, the best outcomes are when FMs are prevented in the first place by empowering those at risk so that they can avoid victimisation through accessing support and protective measures like FMPOs.

\section{Notes}

1. In February 2003, Iftikhar and Farzana Ahmed took their daughter Shafilea to Pakistan against her will for the purpose of forcing her into marriage. In an effort to prevent this, Shafilea ingested bleach. As a result of her injuries, Shafilea was no longer considered eligible for marriage and was brought back to the UK (removed for review). Shafilea disappeared from her family's home on the night of 11 September 2003. The circumstances of her disappearance were treated as suspicious from the start for many reasons, not least the documented history of parental abuse (removed for review). On 4 February 2004, the decomposed remains of a human body were found on the banks of the River Kent near Force Bridge. Both Iftikhar and Farzana were eventually convicted of Shafilea's murder and received life sentences on 3 August 2012 (removed for review).

2. Regina $v M$ and $B$ came before Leeds Crown Court in May 2018 and involved a young woman who was nineteen at the time of the attempted FM. The young woman, who was studying for her A-Levels at the time, was taken out of college during term-time 
for what she thought was a six-week family holiday to Bangladesh. However, while overseas her parents revealed that she was to marry her first cousin: a marriage that had been planned for some time. The young woman refused and sought the support of her mother, but her mother made it clear that this was a shared parental plan. She told her daughter that refusing was not an option and that, if necessary, violence would be used; the young woman's father also issued a threat when she refused to cooperate. Days before the wedding, the young woman's sister alerted the British High Commission in Bangladesh, who worked with the UK's FMU and the Bangladeshi police to protect the young woman and bring her back to the UK (Perraudin 2018). Her parents were found guilty of using violence and coercion to force her to marry against her will. They were sentenced at Leeds Crown Court on 30 July 2019, the father to four-and-a-half years and the mother to three-and-a-half years (Perraudin 2018).

\section{References}

Authors (2017/18/19) Removed from review.

Anitha, S. (2019) Understanding economic abuse through an intersectional lens: Financial abuse, control and exploitation of South Asian women's productive and reproductive labour. Violence Against women (forthcoming).

Callaghan, J., Alexander, J.., Sixsmith, J., Fellin, L. (2018) Beyond “Witnessing”: Children’s Experiences of Coercive Control in Domestic Violence and Abuse. Journal of Interpersonal Violence, 33(10), 1551-1581.

Chantler, K. and McCarry, M. (2019) Forced marriage, coercive control, and conducive contexts: the experiences of women in Scotland, Violence Against Women, 1-33. 
Crown Prosecution Service (2017) Crown Prosecution Service - Honour Based Violence and Forced Marriage. Available at:

http://www.cps.gov.uk/legal/h to k/honour based violence and forced marriagel

Dickens, J., Masson J., Garside, L., Young, J. and Bader, K. (2019) Courts, care proceedings and outcomes uncertainty: The challenges of achieving and assessing "good outcomes" for children after child protection proceedings., Child \& Family Social Work. 2019;1-8.

Family Court Statistics Quarterly (2019) Family Court Statistics Quarterly, October to December 2018. Available at: https://www.gov.uk/government/statistics/family-court$\underline{\text { statistics-quarterly-october-to-december-2018 }}$

FMU (2017) Forced Marriage Unit statistics (2017) London: Home Office and Foreign \& Commonwealth Office.

FMU (2018) Forced Marriage Unit statistics (2017) London: Home Office and Foreign \& Commonwealth Office.

Gangoli, G., Razak, A. and McCarry, M. (2006) Forced marriages and domestic violence among South Asian communities in North East England. Newcastle \& Bristol: Northern Rock Foundation \& University of Bristol.

Hallett, S. (2017) Making sense of child sexual exploitation. Exchange, abuse and young people. Bristol: Policy Press.

Henderson, E. (2015) 'A very valuable tool’: Judges, advocates and intermediaries discuss the intermediary system in England and Wales. Outtara, M., Sen, P. and Thompson, M. (1998) 'Forced marriage, forced sex: The perils of childhood for girls', Gender and Development 6 (3): 27-33. 
Hester, M., Chantler, K., Gangoli, G. (2008) Forced marriage: The risk factors and the effect of raising the minimum age for a sponsor, and of leave to enter the UK as a spouse or fiancé(e), University of Bristol and School of Nursing, Midwifery and Social Work, University of Manchester.

Huey, L. (2010). 'I've seen this on CSI': Criminal investigators' perceptions about the management of public expectations in the field. Crime, Media, Culture, 6(1), 49-68.

Jamieson, A. (2001). Transnational Organised Crime: A European Perspective, Studies in Conflict and Terrorism, 24: 377-387.

Longman, C. and Bradley, T. (2015). (Eds.) Interrogating Harmful Cultural Practices: Gender, Culture and Coercion, London: Routledge.

Love, H., Dank, M., Esthappan, S., Zweig, J. (2019) Navigating an Unclear Terrain: Challenges in Recognizing, Naming, and Accessing Services for “Forced Marriage.” Violence Against Women, 25(9), 1138-1159.

Mayeda, T., Cho, S., and Vijaykumar, R. (2019) Honor-based violence and coercive control among Asian youth in Auckland, New Zealand, Asian Journal of Women's Studies, 25:2, 159179.

Munro, V. (2010) From consent to coercion: evaluating international and domestic frameworks for the criminalization of rape. In: McGlynn, C. and Munro, Vanessa, (eds.) Rethinking Rape Law: International and Comparative Perspectives. Oxon, U.K.; New York, N.Y. Routledge, pp. 17-29.

Perraudin, F. (2018) UK couple found guilty of trying to force daughter to marry. Available at: https://www.theguardian.com/uk-news/2018/may/29/couple-found-guilty-attemptedforced-marriage-daughter 
Plotnikoff, J., Woolfson, R. (2015) Intermediaries in the Criminal Justice System: Improving Communication with Vulnerable Witnesses and Defendants. Bristol: Policy Press.

Summers, H. (2018) Birmingham woman jailed for duping daughter into forced marriage.

Available at: https://www.theguardian.com/uk-news/2018/may/23/birmingham-womanjailed-duping-daughter-forced-marriage

Schuller, R., Rzepa, S. (2002) Expert Testimony Pertaining to Battered Woman Syndrome: It’s Impact on Jurors' Decisions, Law and Human Behaviour, 26 (6), 655-673.

Schweitzer, N., Saks, M. (2007) The 'CSI-effect': Popular fiction about forensic science affects the public's expectations about real forensic science, Jurimetrics, 47, 357-364.

Skidmore, M., Garner, S., Crocker, R., Webb, S., Graham, J. and Gill, M. (2016) Organised crime and child sexual exploitation in local communities. London: The Police Foundation and Perpetuity Research. 